Rita de Cássia Oliveira da Costa Mattos (iD) http://orcid.org/0000-0002-0523-7467

Hermano Albuquerque de Castro ${ }^{a}$ (D) https://orcid.org/0000-0003-1191-5671

Ana Luiza Michel Cavalcante ${ }^{a}$

(D) https://orcid.org/0000-0002-2338-6060

Elizabeth Dias

(iD) https://orcid.org/0000-0003-1708-1014

a Fundação Oswaldo Cruz (Fiocruz), Centro de Estudos da Saúde do Trabalhador e Ecologia Humana. Rio de Janeiro, RJ, Brasil.

Contato:

Rita de Cássia Oliveira da Costa Mattos E-mail:

rcocmattos@gmail.com

Os autores declaram que o estudo não foi subvencionado e que não há conflitos de interesses.

Os autores informam que o trabalho não foi apresentado em eventos científicos e que não foi baseado em dissertação ou tese.

\section{Formação profissional como ação estratégica para implementação da Política Nacional de Saúde do Trabalhador e da Trabalhadora}

\author{
Professional qualification as a strategic action for the \\ implementation of the Brazilian Workers' Health Policy
}

\section{Resumo}

Introdução: a criação da Rede Nacional de Atenção Integral à Saúde do Trabalhador é considerada a principal estratégia para a Política Nacional de Saúde do Trabalhador e da Trabalhadora. O Ministério da Saúde priorizou a qualificação profissional das equipes dos centros de referência em saúde do trabalhador, considerados nucleares na rede. Foi firmado um convênio com o Centro de Estudos da Saúde do Trabalhador e Ecologia Humana, da Escola Nacional de Saúde Pública, da Fundação Oswaldo Cruz, para o desenvolvimento de um Curso de Especialização em Saúde do Trabalhador na modalidade a distância. Objetivo: descrever e analisar o desenvolvimento do curso no período de 2006 a 2015. Métodos: análise documental. Resultados: o curso ocorreu nas regiões Norte, Nordeste, Centro-Oeste e Sudeste, com 1.703 inscritos, $70 \%$ de concluintes aprovados e evasão de $28 \%$. Valorizou-se a opinião dos profissionais participantes sobre o curso e o material didático e analisou-se sua relação com a política e o desempenho dos alunos e tutores. Conclusão: o processo pioneiro cumpriu os objetivos abrindo novos caminhos para ações em saúde do trabalhador e identificando evidências positivas da capacitação sobre os serviços e a rede.

Palavras-chave: saúde do trabalhador; política nacional de saúde do trabalhador; formação profissional; educação a distância.

\begin{abstract}
Introduction: the creation of the National Workers' Health Comprehensive Care Network is considered the main strategy for the Brazilian Workers' Health Policy. The Ministry of Health prioritized the professional training of the teams from workers' health reference centers, which are considered crucial within the network. The Ministry of Health signed an agreement with the Centre of Studies for Worker's Health and Human Ecology of the Oswaldo Cruz Foundation National School of Public Health, aiming at organizing a distance education course on Workers' Health. Objective: to describe and analyze the course development from 2006 to 2015. Methods: documentary analysis. Results: the course was held in the North, Northeast, Midwest and Southeast regions of Brazil, with 1,703 enrollees, from which $70 \%$ were approved and $28 \%$ dropped out. The participants' opinions about the course and its materials were taken into account. We analyzed the relationship between the course and the workers' health policy, as well as the performance of students and tutors. Conclusion: the courses pioneering process achieved its objectives, carving new paths for actions in workers' health, and making it possible to identify positive evidence of the training on services and the network.
\end{abstract}

Keywords: occupational health; Brazilian workers' health policy; professional qualification; distance education. 


\section{Introdução}

A qualificação dos trabalhadores de saúde é reconhecida como estratégia essencial para o fortalecimento do Sistema Único de Saúde (SUS) ${ }^{1}$, em particular em áreas menos tradicionais de atuação, como a saúde mental, do idoso e do trabalhador ${ }^{2}$. Nos anos 1980, a Educação Permanente em Saúde (EPS) foi adotada como Programa de Desenvolvimento de Recursos Humanos pela Organização Pan-Americana de Saúde (Opas) nos países membros. No Brasil, o Ministério da Saúde (MS) criou, em 2003, a Secretaria de Gestão do Trabalho e da Educação na Saúde, com a responsabilidade de formular políticas orientadoras da gestão, formação, qualificação e regulação dos trabalhadores da saúde, ações consolidadas em 2004 na Política Nacional de Educação Permanente em Saúde (PNEPS) ${ }^{3,4}$. A construção da atenção integral à saúde dos trabalhadores no SUS, em cumprimento ao preceito constitucional, regulamentado pelo Artigo $6^{\circ}$ da Lei $\mathrm{n}^{\circ} 8.080$, de 19 de setembro de 1990, apresentou grande avanço com a criação da Rede Nacional de Atenção Integral à Saúde do Trabalhador (Renast) ${ }^{5}$ em 2002. Para sua operacionalização, a Coordenação Geral de Saúde do Trabalhador (CGSAT/MS), área técnica do MS, priorizou a qualificação das equipes dos centros de referência em saúde do trabalhador (Cerest), considerados nós estratégicos dessa rede ${ }^{6}$.

Para atender a necessidade de qualificar profissionais em escala e em curto período, considerando a extensão e a diversidade regional brasileira, em especial as especificidades da região amazônica, a CGSAT/ MS firmou convênio com o Centro de Estudos da Saúde do Trabalhador e Ecologia Humana (Cesteh), da Escola Nacional de Saúde do Pública (Ensp), da Fundação Oswaldo Cruz (Fiocruz) para o desenvolvimento de um curso de Especialização em Saúde do Trabalhador na modalidade à distância (Cest-AD).

Registre-se que o Cesteh acumulava, naquele momento, grande experiência na formação de profissionais no campo da saúde do trabalhador, uma vez que foi pioneiro ao oferecer curso presencial de especialização na área, em 1986, ano da realização da VIII Conferência Nacional de Saúde e da I Conferência Nacional de Saúde do Trabalhador. Isso potencializado pela experiência com processos de educação a distância (EAD) da Ensp credenciou-o a assumir o desafio ${ }^{7-9}$. Para facilitar a elaboração da proposta e a articulação entre as instâncias envolvidas foi criada uma comissão coordenadora composta por representantes do Cesteh, do EAD/Ensp e da CGSAT/MS.

Priorizou-se a capacitação de profissionais do território da Amazônia Legal, que corresponde à área dos estados da região Norte (Acre, Amapá, Amazonas, Pará, Rondônia, Roraima e Tocantins), de Mato Grosso e de parte do Maranhão. Também foi priorizado o estado do Piauí. Deu-se destaque especial para a formação dos profissionais dos dez Cerest estaduais, localizados em Rio Branco, Macapá, Manaus, São Luiz, Cuiabá, Belém, Porto Velho, Boa Vista, Palmas e Teresina e cinco Cerest regionais: Imperatriz, Belém, Marabá, Santarém e Palmas ${ }^{10}$.

O objetivo deste estudo é apresentar e analisar a trajetória do Curso de Especialização em Saúde do Trabalhador na modalidade à distância, no período 2006 a 2015, enquanto ação estratégica da Política Nacional da Saúde do Trabalhador e da Trabalhadora (PNSTT), abrangendo a definição dos objetivos, estrutura e conteúdo do curso. São descritos e analisados a construção da proposta do curso, a preparação do material didático, a formação dos tutores, a implementação das turmas e os resultados, a partir do quadro de egressos e dos processos de avaliação ${ }^{11,12}$. Em 2016 foram implementadas alterações na proposta de curso e novas turmas foram iniciadas, mas não constam deste relato.

\section{Métodos}

Adotou-se o método de análise documental, que desvela aspectos novos de um tema ou problema utilizando como fontes os projetos, os relatórios institucionais, os pareceres, as fotografias, as atas de reuniões e os ofícios considerados como base do trabalho de investigação ${ }^{13,14}$.

Helder ${ }^{15}$ afirma que a técnica documental utiliza documentos originais, que ainda não receberam tratamento analítico por nenhum autor, contribuindo sobremaneira para a pesquisa em ciências sociais e humanas. Essa metodologia leva em conta a coleta de dados que minimiza a influência de intervenção do pesquisador. Assim, a pesquisa documental é um procedimento que se utiliza de métodos e técnicas para a apreensão, compreensão e análise de documentos dos mais variados tipos.

O conceito de documento é muito amplo e dispõe de várias interpretações, não sendo fácil sua definição. Um documento é qualquer registro de informações, independentemente do formato ou do suporte utilizado para registrá-las. Instituída pela ciência arquivística, a definição possui caráter generalista, o que significa que certas ciências ou alguns de seus ramos especializados podem adotar definições mais específicas ${ }^{15}$.

Neste estudo, os documentos utilizados foram informativos, de origem comprobatória, textuais e públicos. Foram avaliados: relatórios gerais emitidos pela Secretaria Acadêmica da Ensp, relatórios 
técnicos apresentados ao MS, artigos científicos e dissertações. Os cursos avaliados ocorreram no período de 2006 a 2015.

As seguintes perguntas nortearam a avaliação do curso:

- O curso contribuiu para o desenvolvimento das políticas universais, intersetoriais, integradas e da inclusão social do trabalhador, prescritas para o SUS e para a Renast?

- O curso contribuiu para que o aluno identificasse, propusesse e implementasse soluções para problemas concretos, considerando o papel do trabalho na determinação do processo saúde-doença e da degradação ambiental?

\section{Resultados e discussão}

A construção e a implementação do Curso de Especialização em Saúde do Trabalhador na modalidade a distância deu-se em quatro etapas iniciadas com a definição das competências básicas para o desenvolvimento da atenção integral à saúde dos trabalhadores, nas três esferas de gestão, que serviram para a estruturação das unidades de aprendizagem (UA): (1) preparação do material didático; (2) capacitação dos tutores; (3) desenvolvimento do curso; (4) acompanhamento e avaliação.

Em dezembro de 2004 foi realizada uma oficina de trabalho em Belém do Pará com a participação de profissionais dos Cerest da região e instituições relacionadas com esfera do trabalho, da Previdência Social, do Ministério Público e das organizações sociais, de acordo com a metodologia adotada pelo $\mathrm{EAD} / \mathrm{Ensp}^{10}$. Conceitualmente a atenção integral à saúde dos trabalhadores articula ações de promoção, proteção, vigilância da saúde, assistência e reabilitação nos diversos níveis de atenção e gestão no âmbito do SUS, em articulação intra e intersetorial.

Formar por competências implica desenvolver a capacidade de mobilizar conhecimentos, habilidades e atitudes para lidar com situações, problemas e dilemas da vida real; bem como certificação, que expressa a legitimação social de pessoas que passam a ser reconhecidas como capazes de atuar na carreira ${ }^{16,17}$. Nessa concepção, o indivíduo se forma pelo diálogo estabelecido entre ele e o contexto. A formação inicia-se a partir de demandas e organiza-se para que os estudantes aprendam por meio de ações - aprender fazendo - e enriqueçam-se com o compartilhamento de experiências ${ }^{18}$. Esse referencial tem sido crescentemente utilizado para orientar processos educativos na saúde. Também foram consideradas as prescrições da Política Nacional de Educação Permanente em Saúde e os princípios da andragogia que se referem à aprendizagem de adultos ${ }^{19,20}$.

Segundo Nunes e Frossard ${ }^{21}$, “os referenciais político-pedagógico assumidos pela Ensp sustentam-se na compreensão de que educação a distância é, antes de tudo, educação” (p. 21). Para as autoras, os processos educativos desenvolvidos a distância não podem abrir mão de uma clara intencionalidade político-pedagógica que engloba a cultura e o contexto histórico-social, do qual o trabalho humano é constituinte. Desse modo, a Ensp concebe a educação como uma prática social construída por meio da participação, do diálogo e dos significados produzidos entre os sujeitos utilizando métodos que constituem uma educação problematizadora e libertadora. Segundo Oliveira ${ }^{22}$, essa abordagem pressupõe a proximidade do educador-educando-conhecimento, numa relação de justaposição como atitude democrática e conscientizadora, favorecendo uma relação de interação, aprendizagem autônoma, criticidade, flexibilidade e escuta.

A matriz das competências produzida serviu de base para a organização do curso em cinco UA compostas de quatorze capítulos. A partir das avaliações periódicas realizadas pelos alunos e tutores e das necessidades identificadas pela coordenação e gestores demandantes, esta estrutura sofreu ajustes no decorrer do tempo, resultando em uma carga horária total de 478 horas, sendo 104 presencias.

O curso se inicia na UA I, com um capítulo desenvolvido presencialmente, com duração de 20 horas, facilitando o vínculo aluno-tutor e favorecendo a cooperação, importante para o sucesso do curso; além de permitir a familiarização com o Ambiente Virtual de Aprendizagem (AVA) e o desenvolvimento de capacidade de crítica e de problematização das questões de saúde relacionadas ao trabalho na região. As demais unidades são desenvolvidas a distância (Figura 1). 


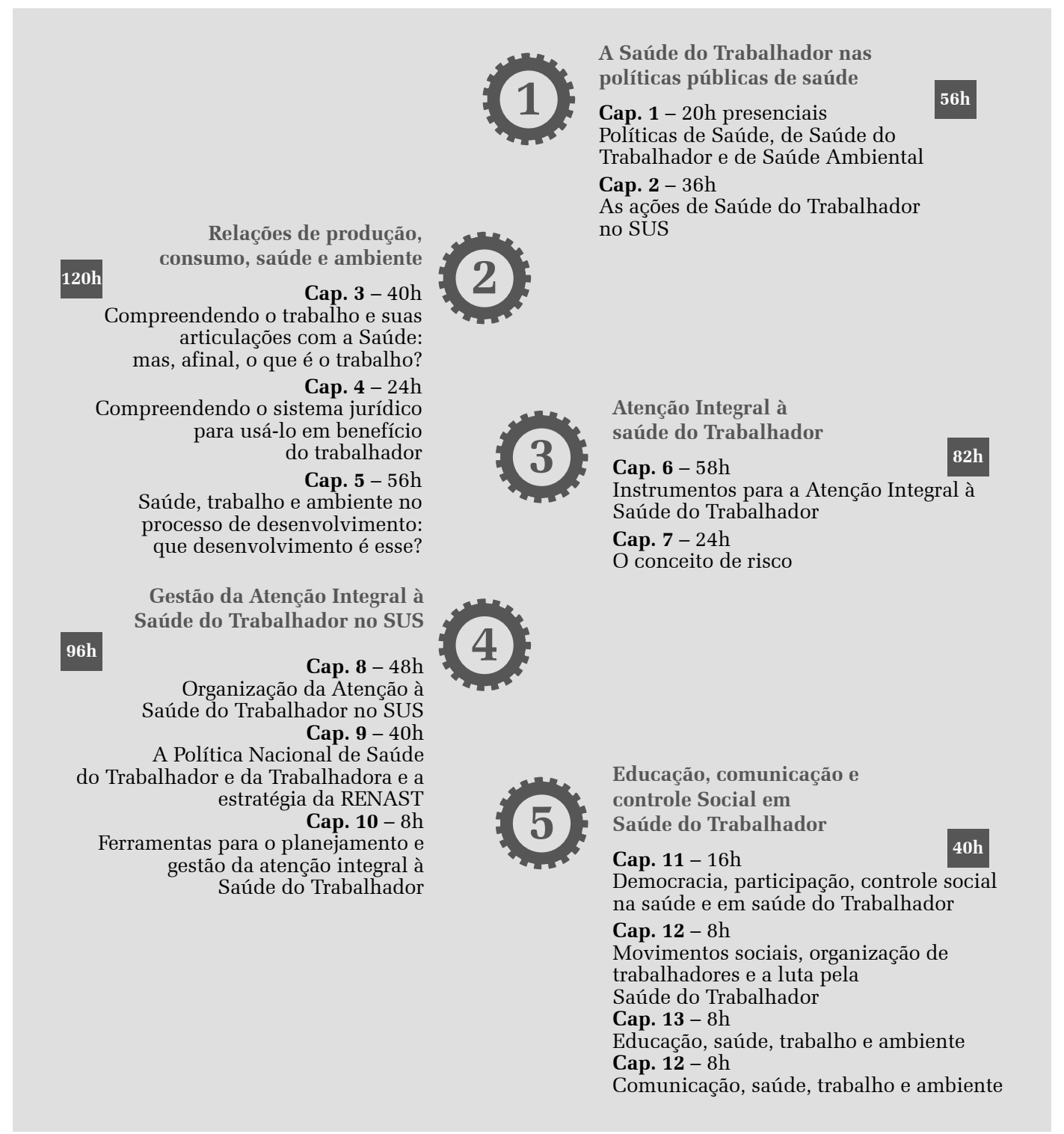

Figura 1 Estrutura do Cest-AD organizada pelas unidades de aprendizagem e eixos temáticos, 2016 Fonte: Nunes e Frossard, $2012^{21}$

Para facilitar a elaboração do Trabalho de Conclusão do Curso (TCC) foram previstas três atividades presenciais ao longo do curso: (1) oficina de Metodologia de Pesquisa, na qual são apresentados os temas e os fundamentos de elaboração do TCC; (2) defesa dos projetos e; (3) qualificação do TCC perante uma banca composta por especialistas. $\mathrm{Na}$ avaliação final presencial, exigência legal do Ministério da Educação (MEC) para os cursos a distância, o aluno defende o TCC perante uma banca julgadora e realiza a prova final $^{23}$.

Com base na estrutura e nos conteúdos das UA foi preparado o material didático e realizada a seleção e capacitação dos tutores. Para elaboração dos textos foram realizadas duas oficinas no Rio de
Janeiro, em que os autores convidados foram acompanhados pela equipe do EAD e da coordenação do curso. Participaram dessa atividade cerca de 140 especialistas, divididos em grupos, de acordo com as afinidades e expertises em sintonia com os domínios das competências.

A elaboração do material didático contou com a contribuição de 70 autores. Os textos produzidos foram revisados pela equipe do EAD e pela coordenação do curso. O produto final foi validado em três oficinas realizadas em 2005, que também serviram para a formação de tutores. O processo de validação, além de qualificar os tutores, enriqueceu a produção do material didático com a incorporação de saberes e experiências, tornando-o mais próximo das realidades regionais. 
Para as primeiras turmas de alunos iniciadas em 2006, a versão final foi disponibilizada nos meios virtual e impresso. Em 2010, as avaliações dos tutores e orientadores de aprendizagem (OA) apontaram a necessidade de revisão desse material, para aperfeiçoamento da linguagem utilizada nos textos e da formulação das atividades. Nesse processo de revisão foram incorporados atividades e textos do Curso de Qualificação de Gestores do SUS, promovido pelo EAD/Ensp, considerando a importância do tema da gestão para os profissionais da Saúde do Trabalhador ${ }^{12}$.

Complementou o material de apoio o Caderno de Orientação do Tutor, concebido como instrumento da educação permanente, que amplia as orientações pedagógicas e aprofunda questões relacionadas ao tema. Nesse sentido, serviu à capacitação técnica, uma vez que muitos não são especialistas na área. Esse caderno abordou: (a) a importância do curso como política estratégica de implementação da Renast, da PNSTT e da Política Nacional de Segurança da Saúde do Trabalhador (PNSST); (b) as concepções pedagógicas; (c) as diretrizes para o acompanhamento acadêmico-pedagógico; (d) os objetivos das atividades do curso; e) o guia de correção das atividades; e (f) os parâmetros acadêmicos para elaboração do TCC $^{12}$.

A tutoria desempenhou um papel fundamental no Curso de Especialização em Saúde do Trabalhador na modalidade a distância, responsável pela mediação entre o material didático e o desenvolvimento e a construção do conhecimento pelo aluno. O tutor atuou como facilitador da aprendizagem fornecendo e trocando informações que possibilitariam ao aluno agir e tomar decisão. Silva e Santana ${ }^{24}$ relacionam conteúdos curriculares e o SUS, e afirmam que os currículos devem ser dotados de competências e habilidades que sejam adequadas às referências nacionais e internacionais para a formação de um profissional crítico-reflexivo, transformador da realidade social, agente de mudança e comprometido com a saúde da população. Nesse sentido, o tutor deve estar preparado para contribuir para a formação desse profissional, respeitando as diferenças loco-regionais.

Outra base pedagógica importante foi atribuída ao OA, um profissional com pós-graduação stricto sensu e experiência na área de saúde do trabalhador que acompanha os tutores e promove o debate de temas no ambiente de formação permanente, nos conteúdos específicos e ampliação de uma visão global e humanizadora, valorizando o trabalho em equipe para a atenção integral à saúde ${ }^{24}$.

Para auxiliar no acompanhamento acadêmico do aluno, o coordenador regional atuou como um representante do curso na sua região, estabelecendo elos entre alunos, tutores e coordenação geral, além de auxiliar na promoção dos momentos presenciais ${ }^{12}$.

A avaliação dos estudantes baseou-se em: (a) acompanhamento das atividades de avaliação; (b) participação nos momentos presencias, fóruns e debates; e (c) elaboração do TCC. Os certificados de conclusão - Especialista em Saúde do Trabalhador - foram expedidos pela Secretaria Acadêmica da Escola Nacional de Saúde Pública da Fundação Oswaldo Cruz.

As primeiras nove turmas do Curso de Especialização em Saúde do Trabalhador na modalidade a distância foram iniciadas em novembro de 2006, nos estados do Amapá, Mato Grosso do Sul e Tocantins. Dos 197 alunos inscritos, 85\% concluíram o curso. Sete novas turmas começaram em 2007 nos estados do Piauí, Maranhão, Rio de Janeiro e São Paulo, com 142 inscritos, sendo que 78\% concluíram. Em 2008, foram oferecidas três turmas em Roraima e uma em São Paulo, com 80 inscritos e 77\% concluintes. Em 2010, duas turmas começaram, uma em Registro/SP e outra no Rio Grande do Norte, com 43 alunos inscritos e 91\% concluintes.

Em 2011, foram oferecidas quatro novas turmas no estado do Mato Grosso do Sul, com 88 alunos inscritos e $67 \%$ concluintes. Cabe ressaltar que este foi um dos estados pioneiros na formação para o campo da ST, pois anteriormente, em 2000 e 2001, já haviam sido ministrados dois cursos semipresenciais, coordenados pelo Cesteh. Em 2013, mais quatro turmas foram abertas: uma em Brasília, destinada a servidores dos ministérios envolvidos com a PNSTT, e duas em São Paulo, com total de 54 alunos inscritos e 62\% concluintes.

Em 2012, o processo ganhou escala, uma vez que, por demanda da Coordenação Estadual de Saúde do Trabalhador de São Paulo, foram iniciadas 33 turmas em 15 municípios desse estado ${ }^{12}$. Em 2000, a Secretaria de Estado da Saúde de São Paulo (SES/SP) criou a Comissão Intra-setorial de Saúde do Trabalhador, em que foram geradas condições institucionais e operacionais para implantação da política no SUS/SP, de forma integrada e sistemática. Essa instância, de caráter coletivo e intrainstituticional, estimulou o debate sobre o tema, congregou os gestores e envolveu o controle social e as instituições afins.

Uma das atribuições dessa comissão era coordenar programas, cursos e projetos de capacitação, treinamento, aperfeiçoamento e educação na área de saúde e trabalho. Após essa estruturação foi elaborado o Plano Estadual de Saúde para a implementação de ações em educação permanente para o SUS ${ }^{25,26}$. O estado de São Paulo foi o primeiro 
do país a apresentar uma rede de Cerest regionais habilitados. Em 2003, já havia 23 Cerest habilitados: 1 estadual, 5 metropolitanos (cidade de São Paulo) e 17 regionais. Em 2004, a previsão era de que todos os 24 municípios-sede de regiões de saúde teriam o seu Cerest regional. Atualmente, São Paulo possui 42 Cerest abrangendo todo o estado ${ }^{26,27}$.

O projeto de Educação Permanente em Saúde do Trabalhador foi estruturado como uma das estratégias da política de qualificação profissional, cujos termos e compromissos foram discutidos e pactuados com os municípios na Comissão Intergestores Bipartite do Estado de São Paulo, que aprovou a implementação do projeto de Educação Permanente em Saúde do Trabalhador (EPS/ST-SUS/SP), publicado na Deliberação CIB n ${ }^{\circ}$ 6/2011. A ampliação da metodologia do ensino na modalidade a distância foi também apontada no Plano Estadual de Saúde (PES) 2012-2015 como um dos objetivos prioritários. A proposta elaborada incluía várias modalidades de formação, dentre elas a realização de cursos de especialização voltados aos profissionais inseridos nos dispositivos de gestão, vigilância e atenção em saúde do SUS/SP. O Curso de Especialização em Saúde do Trabalhador na modalidade a distância foi apontado na CIB n $n^{\circ}$ 6/2011 como opção para a especialização dos profissionais do SUS/SP. A adesão de 15 Cerest regionais resultou na formação de turmas compostas por 740 profissionais dos seguintes centros: Marília, Bauru, Mauá, Franca, Jundiaí, Ribeirão Preto, Indaiatuba, Bebedouro, São João da Boa Vista, Osasco, Franco da Rocha, Presidente Prudente, Sorocaba, Itapeva e Araraquara.

Sintetizando, no período 2006 a 2015 foram inscritos 1.703 profissionais em 81 turmas, resultando em 1.591 alunos efetivos. Destes, 1.114 concluíram o curso (70\%) e 33 foram reprovados (2\%). Nesse período, o número de formandos foi bastante satisfatório, apresentando um percentual de evasão de apenas 28\% (444 alunos).

Ao analisarmos os dados nacionais por região (Figura 2), observamos que o maior percentual de evasão está na região Sudeste (34\%), embora não possa ser considerado alto para cursos EAD. Um dos fatores contribuintes para o problema foram as trocas de gestão municipal em virtude de eleições. Muitas das novas gestões não se sentiram comprometidas com o projeto e alguns alunos não conseguiram concluir o curso. Vale ressaltar que, para a seleção do aluno, ele devia apresentar uma carta do gestor autorizando sua inscrição, bem como a sua disponibilização de 8 horas semanais para as atividades do curso. Além disso, alguns coordenadores regionais também foram afastados, gerando mais um importante fator para a evasão.

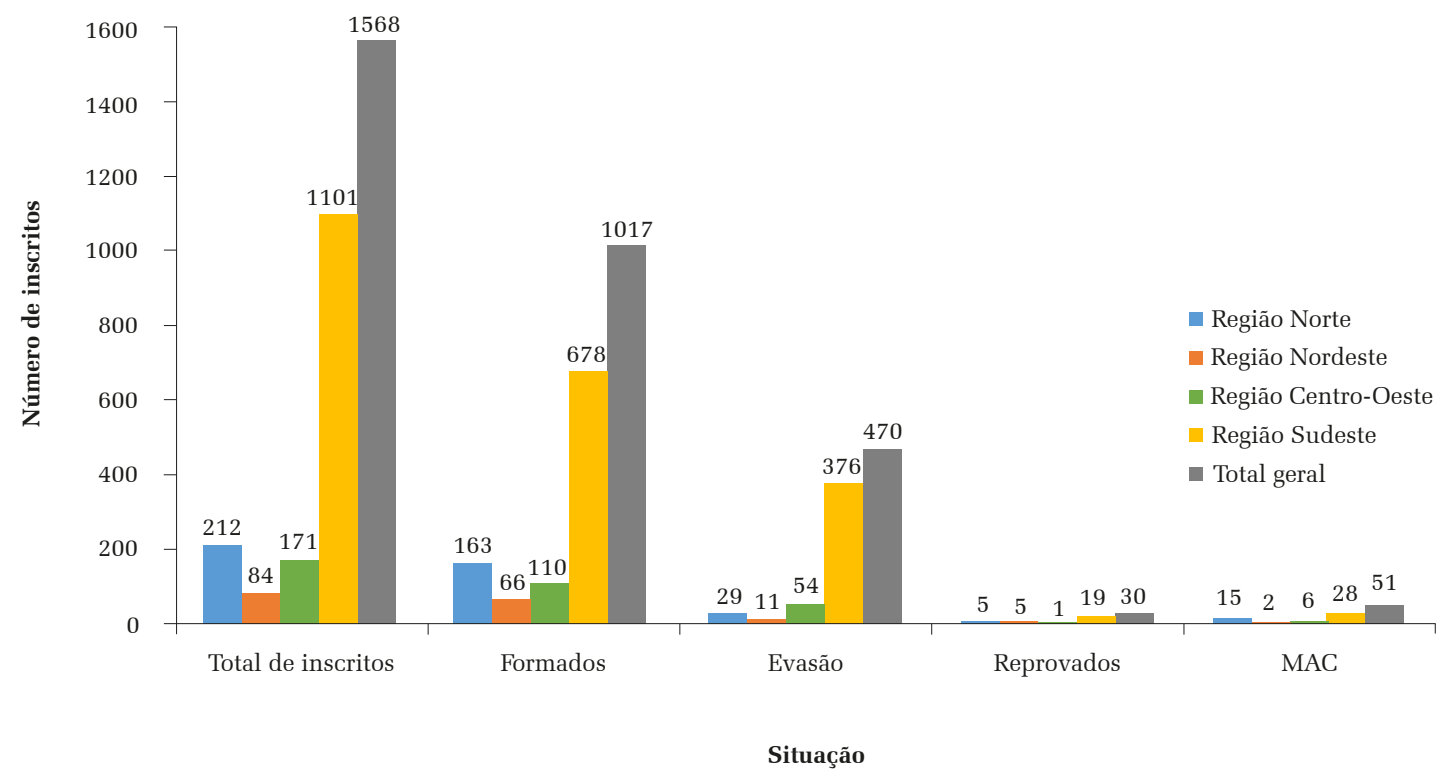

MAC: Matrícula Automaticamente Cancelada.

Região Norte: Boa Vista (RR), Imperatriz (MA), Macapá (AP), Palmas (TO).

Região Nordeste: Natal (RN), Teresina (PI).

Região Centro-Oeste: Brasília (DF), Campo Grande (MS), Corumbá (MS), Dourados (MS).

Região Sudeste: Rio de Janeiro (RJ); no estado de São Paulo: Cruzeiro, Registro, Mauá, Araraquara, Itapeva, Indaiatuba, Marília, Franca, São

João da Boa Vista, Jundiaí, Bauru, Osasco, Ribeirão Preto, Sorocaba, Presidente Prudente, Bebedouro, Franco da Rocha e Núcleo de Saúde do Trabalhador (MS).

Figura 2 Distribuição dos inscritos por região no período de 2006 a 2016. 
As dificuldades com o uso da tecnologia e a taxa de evasão são reconhecidas na literatura. Na região Norte esse fato foi determinante em decorrência de deficiência no acesso a ferramentas tecnológicas. Para vencer esse osbstáculo, a tutoria promoveu de forma criativa inúmeras atividades, como: ida à universidade local para utilização de uma melhor rede, encontros locais para discutir presencialmente as atividades e uso de e-mails ${ }^{28}$.

Segundo Martins ${ }^{28}$, gênero, idade, escolaridade e área de atuação profissional são possíveis variáveis que explicam o sucesso ou o insucesso do aluno de curso a distância. Dos matriculados e concluintes, $82 \%$ são do sexo feminino, refletindo a feminização da força de trabalho em saúde. Esse termo é atribuído ao processo de mulheres em profissões anteriormente masculinas. Machado, Oliveira e Moyses ${ }^{29}$ analisaram os dados censitários da década de 2000 no Brasil relativos à força de trabalho em saúde, observando que, do total de 709.267 profissionais com escolaridade universitária, 62\% eram mulheres. Em algumas profissões, esse processo de feminização é mais recente e de forte impacto, estimando-se que nas próximas duas décadas esse percentual deve atingir $50 \%{ }^{27}$.

Não se observou diferença entre as idades no que se refere à conclusão do curso. Metade dos alunos tinha entre 31 e 46 anos, podendo ser considerados profissionais em meio de carreira, o que, em tese, potencializa o investimento na qualificação e aponta para a necessidade de continuidade do processo. Também reforça a necessidade de acompanhamento dos egressos, no sentido de evidenciar os impactos para a rede de saúde e a inclusão da saúde do trabalhador nas práticas e políticas de saúde ${ }^{12}$. Um dado apontado no censo escolar da EAD $(2010 / 2011)^{30}$ é que $47 \%$ dos alunos matriculados na modalidade EAD estão na faixa etária acima de 30 anos, indicando que muitos deles nasceram e cresceram em um modelo de educação baseado na direcionalidade do ensino, em que o professor ensinava e o aluno tinha uma participação mais passiva em seu processo de aprendizagem. No nosso estudo não foi possível aprofundar a influência da idade no desempenho do aluno, o que merece uma avaliação mais apurada.

Sobre a qualificação e o acompanhamento dos tutores, foi dedicada especial atenção para a oficina de formação inicial, as atividades de atualização e o suporte dos OA. No estado de São Paulo, em maio de 2013, foi realizada uma oficina de formação continuada com o objetivo de acompanhar o desenvolvimento das atividades, identificar dificuldades no sentido de corrigi-las, e facilitar a troca de experiências no grupo. Também serviu para apoiar o desenvolvimento dos TCC e o trabalho dos coordenadores regionais e dos OA. Participaram da atividade cerca de 70 profissionais $^{12}$.

\section{Sobre os TCC}

Os TCC foram orientados por professores de universidades e instituições de ensino e pesquisa da região, que são credenciados como orientadores externos pela Ensp ou por tutores, com o apoio dos OA e de pesquisadores do Cesteh ${ }^{12}$.

Nesse período foram elaborados 970 TCC, abordando temas definidos como de interesse para o desenvolvimento da Renast e construção do campo da Saúde do Trabalhador no SUS. Uma análise dos temas e metodologias escolhidos revelou que $68 \%$ são revisões bibliográficas, com nota média de 8,6 (conceito B) ${ }^{11,12}$.

Considera-se que os TCC têm importância estratégica para a produção de conhecimento e apoio à implementação da PNSTT. Eles refletem, além dos interesses individuais, dos alunos e dos orientadores, as necessidades de conhecimento e saberes sistematizados sobre os problemas cotidianos de saúde dos trabalhadores e do ambiente na região em que o aluno vive.

Inicialmente, foram definidos temas considerados prioritários pelas equipes dos Cerest e supervisores do MS para serem desenvolvidos pelos alunos, que após avaliações levaram a uma flexibilização na escolha dos temas. Os assuntos mais estudados foram: Vigilância em saúde do trabalhador, saúde mental, lesões por esforços repetitivos (LER)/distúrbios osteomusculares relacionados ao trabalho (Dort), biossegurança, ergonomia, toxicologia, perda auditiva induzida por ruído (Pair), trabalho em saúde, rural e infantil ${ }^{11,12}$.

\section{Aprendizagens no processo}

Apesar de não se dispor de avaliação sistemática de processo e dos resultados, existem indícios de acerto da proposta. É importante lembrar que o crescimento da oferta de cursos EAD, no processo de ensino-aprendizagem, obriga ao desenvolvimento de novas estratégias de avalição dos alunos, dos processos pedagógicos e dos resultados e impactos obtidos.

Segundo Lachi, Rocha e Oeiras ${ }^{31}$, o Institute for Higher Education Policy, cujo objetivo é garantir o acesso a um ensino superior de qualidade, propõe 24 indicadores considerados como um referencial de excelência internacional, dos quais incluem: (a) o suporte institucional; (b) os materiais instrucionais revisados periodicamente; (c) o processo ensino-aprendizagem; (d) a estruturação do curso, que inclui o acesso a recursos de biblioteca, inclusive a biblioteca virtual; (e) serviços de suporte efetivos aos alunos e professores; e (f) a avaliação de resultados esperados da aprendizagem. 
No Brasil, o MEC, por meio da Secretaria de Educação a Distância, elaborou um conjunto de 10 diretrizes gerais, cujo objetivo principal é orientar alunos, professores, técnicos e gestores de instituições de ensino superior a buscar a qualidade em seus processos e produtos ${ }^{32}$.

Os resultados desse processo contribuíram para a correção das dificuldades identificadas e para o aperfeiçoamento da proposta, favorecendo a divulgação e a multiplicação do curso, com adaptações e subsídios para o processo de revisão do material didático. Entre os aspectos positivos e potencialidades, destaca-se a interação aluno-tutor/OA/coordenador regional. Esta interação indica ser a responsável pelos resultados positivos da iniciativa, como a baixa evasão. Várias alternativas foram aplicadas nesse curso e contribuíram para seu êxito, por exemplo: os plantões presenciais, a busca ativa de alunos, o apoio na elaboração do TCC, discussões de conteúdos complementares sobre saúde do trabalhador, esclarecimento de dúvidas sobre o uso da plataforma, além dos encontros entre todos os participantes do curso, contribuindo para alunos/profissionais de saúde mais conscientes de suas ações. Outro aspecto importante foi a aproximação com profissionais das universidades e institutos de pesquisa, e dos Cerest com os alunos e gestores municipais ensejando novos olhares sobre os processos de educação permanente ${ }^{12}$.

Na avaliação do curso, o AVA foi considerado como adequado, embora em alguns locais as dificuldades tecnológicas necessitaram de ajustes. Diversos problemas como: prazos, limitações para lidar com as novas metodologias e conflitos intrínsecos ao campo da saúde do trabalhador foram minimizados pela cooperação e interação mútua da equipe EAD e coordenação do curso em busca de soluções.

Como desdobramento positivo do Cest-AD a ser ressaltado, observou-se a criação de redes locais e regionais com a participação dos alunos e de todos os profissionais envolvidos, extrapolando os temas relacionados ao curso.

Foi constatado que o processo de construção do curso resultou em um material didático de alta qualidade, que necessita de revisão, atualização e complementação constantes. Este ponto é sempre ressaltado nas avaliações feitas por todos os profissionais envolvidos ${ }^{8}$.

Outro grande desafio que necessita de investimento técnico e político é o fortalecimento das redes criadas local e regionalmente para a capacitação de profissionais em atenção integral à saúde dos trabalhadores, por meio da transferência do material e das experiências acumuladas. Espera-se que novas possibilidades sejam oferecidas a partir da Renast e da
Rede Nacional de Escolas de Saúde Pública, que têm na Ensp/Fiocruz seu principal apoio.

A presença de alunos e tutores vinculados à atenção básica do SUS sinalizou a possibilidade de ampliação das ações de saúde do trabalhador, que além de porta de entrada do sistema, é considerada coordenadora do cuidado. No contexto do crescimento do trabalho informal e precarizado, inclusive intra domiciliar, cresce a importância da atuação das equipes da atenção básica e saúde da família para o cuidado da saúde desses trabalhadores ${ }^{33}$.

\section{Conclusões e recomendações}

Foram analisados os aspectos pedagógicos do curso e seus impactos sobre as ações de saúde do trabalhador no SUS e na Renast. Valorizou-se conhecer a opinião dos profissionais envolvidos sobre a importância do curso e do material produzido, e da sua integração com as políticas; bem como analisar o desempenho dos alunos e tutores no processo de elaboração e correção das atividades e a adequação dos TCC à proposta inicial do curso. A partir dessa avaliação foi possível identificar evidências positivas da capacitação propiciada pelo Curso de Especialização em Saúde do Trabalhador na modalidade a distância sobre os serviços de saúde e a Renast.

Esse processo pioneiro cumpriu os objetivos propostos e abriu novos caminhos para a capacitação profissional necessária para apoiar a implementação das ações de saúde do trabalhador no SUS e da estratégia da Renast. Apesar de não se dispor de uma avaliação sistemática do impacto do curso, indícios importantes apontam sua relevância para a implementação do PNSTT. Desafios colocados desde o início do projeto e não implementados referem-se ao acompanhamento dos egressos e à definição de indicadores de avaliação do impacto em Saúde do Trabalhador.

As bases conceituais e operacionais fornecidas pelos autores que têm se dedicado ao tema da educação e, mais recentemente, à educação a distância e à experiência acumulada pela equipe do EAD/Ensp ao longo dos últimos anos, serviram de suporte ao estudo e permitiram a aprendizagem de novos conceitos e processos que serão incorporados e socializados com outros grupos e instituições dedicadas à formação de pessoas em saúde.

No atual contexto de perdas de direitos adquiridos que impactam diretamente na proteção social, na saúde e organização dos trabalhadores, a formação de profissionais que atuem no enfrentamento desse cenário de forma ativa é de fundamental importância. Segundo Minayo-Gomez, Vasconcellos e Machado ${ }^{34}$, 
com a criação da Renast, a área avançou especialmente no aspecto formativo, mas ainda carece de fortalecimento, de ampliação e de articulações. Assim, experiências exitosas como o projeto de formação do Curso de Especialização em Saúde do Trabalhador na modalidade a distância devem ser estimuladas, pois ampliam a capacidade e a possibilidade de constituição de uma Renast capacitada e mais fortalecida em defesa da saúde dos trabalhadores.
Quanto aos desafios, o maior deles talvez seja a criação de uma estrutura capaz de atender às novas demandas de turmas. Não menos complexa e importante é a necessidade constante de revisão do material didático, incorporando as críticas e as sugestões produzidas pelo estudo. A avaliação do curso e seus impactos diretos no campo da saúde do trabalhador permitirão desenvolver outras tecnologias pedagógicas.

\section{Contribuições de autoria}

Os autores contribuíram igualmente no desenvolvimento do projeto de pesquisa e na elaboração e aprovação deste artigo.

\section{Referências}

1. Ministério da Saúde. Secretaria-Executiva. Secretaria de Gestão do Trabalho e da Educação na Saúde. Glossário temático: gestão do trabalho e da educação na saúde. 2. ed. Brasília: Ministério da Saúde; 2013. (Série A. Normas e Manuais Técnicos).

2. Lemos CLS. Educação Permanente em Saúde no Brasil: educação ou gerenciamento permanente? Ciênc Saúde Coletiva. 2016;21(3):913-22.

3. Ministério da Saúde. Portaria GM/MS no 198 , de 13 de fevereiro de 2004. Institui a Política Nacional de Educação Permanente em Saúde como estratégia do Sistema Único de Saúde para a formação e o desenvolvimento de trabalhadores para o setor e dá outras providências. Diário Oficial da União, Brasília, DF, 2004 fev 16;1:37-41.

4. Ministério da Saúde. Portaria GM/MS no 1.996 de 20 de agosto de 2007. Dispõe sobre as diretrizes para a implementação da política nacional de educação permanente em saúde e dá outras providências. Diário Oficial da União, Brasília, DF, 2007 ago 20;1:34-8.

5. Ministério da Saúde. Portaria GM/MS n ${ }^{0} 1.679$, de 19 de setembro de 2002. Dispõe sobre a estruturação da rede nacional de atenção integral à saúde do trabalhador no SUS e dá outras providências [Internet]. 2002 [acesso em 2019 jun 18]. Disponível em: http:/ftp.medicina.ufmg.br/osat/legislacao/ Portaria_1679_12092014.pdf

6. Ministério da Saúde. Portaria $\mathrm{n}^{0} 1.823$, de 23 de agosto de 2012. Institui a Política Nacional de Saúde do Trabalhador e da Trabalhadora. Diário Oficial da União. 2012 ago 24;1:46-51.

7. Carvalho AI, Dupret LM. Educação a distância como estratégia de implementação de política pública: experiência da EAD-ENSP/FIOCRUZ. Anais do XI Congreso Internacional del CLAD sobre la Reforma del Estado y de la Administración Pública; 2006 nov 7-10; Ciudad de Guatemala. Caracas: CLAD; 2006.
8. Santos MBM. Avaliação do curso de especialização em saúde do trabalhador e ecologia humana a distância: a importância da escuta dos egressos para o aprimoramento do processo formativo em saúde do trabalhador [dissertação]. Rio de Janeiro: Fundação Oswaldo Cruz; 2009.

9. Ramos JCL. Especialização em Saúde do Trabalhador no Brasil: estudo dos cursos realizados no período de 1986 a 2006 [dissertação]. Salvador: Universidade Federal da Bahia; 2008.

10. Marcondes FD. Contribuição para a formatação de um projeto de Educação Permanente em Saúde do Trabalhador em larga escala para a RENAST. Brasília; 2004. Mimeografado.

11. Fundação Oswaldo Cruz. Proposta de Matriz para o Curso de Especialização em Saúde do Trabalhador e Ecologia Humana a Distância [relatório técnico]. Rio de Janeiro: Fiocruz; 2006 abr 5.

12. Fundação Oswaldo Cruz. Acompanhamento e avaliação do Curso de Especialização em Saúde do Trabalhador e Ecologia Humana na modalidade a distância. Rio de Janeiro: Fiocruz; 2016. (Relatório Técnico CEST-AD 2005-2015).

13. Lüdke M, André MEDA. Pesquisa em educação: abordagens qualitativas. São Paulo: EPU; 1986.

14. Santos AR. Metodologia Científica: a construção do conhecimento. 3. ed. Rio de Janeiro: DP\&A; 2000.

15. Revista Brasileira de História \& Ciências Sociais. Santa Vitória do Palmar: Universidade Federal do Rio Grande. Ano 1, n. 1, jul 2009. ISSN: 2175-3423.

16. Perrenoud P. Construir as competências desde a escola. Porto Alegre: Artes Médicas; 1999.

17. Gontijo ED, Alvim C, Megale L, Melo JRC, Lima MECC. Matriz de competências essenciais para a formação e avaliação de desempenho de estudantes de medicina. Rev Bras Educ Med [Internet]. 2013 [acesso em 2018 mar 5];37(4):526-39. Disponível em: http:/www.scielo.br/pdf/rbem/v37n4/ a08v37n4.pdf 
18. Dewey J. Democracy and education: an introduction to the philosophy of education. New York: The Free Press; 1997.

19. Ministério da Saúde. Secretaria-Executiva. Subsecretaria de Assuntos Administrativos. Educação Permanente em Saúde: um movimento instituinte de novas práticas no Ministério da Saúde: Agenda 2014. 1. reimpr. Brasília, DF: Ministério da Saúde; 2014. p. 120.

20. Carvalho JA, Carvalho MP, Barreto MAM, Alves FA. Andragogia: considerações sobre a aprendizagem do adulto. Ensino, Saúde e Ambiente [Internet]. 2010 [acesso em 2019 jun 17];3(1):78-90. Disponível em: http://periodicos.uff.br/ensinosaudeambiente/article/ view/21105/12579

21. Nunes ST, Frossard V. Curso Saúde do Trabalhador e Ecologia Humana: caderno do aluno. Rio de Janeiro: Fiocruz; 2012. 104 p.

22. Oliveira AL. Uma abordagem da andragogia freiriana na modalidade ead. Educação a Distância (Batatais) [Internet]. 2012 [acesso em 2019 jun 17];2(1):29-45. Disponível em: https://intranet. redeclaretiano.edu.br/download?caminho=upload/ $\mathrm{cms} /$ revista/sumarios/64.pdf\&arquivo=sumario3.pdf

23. Ministério da Educação. Conselho Nacional de Educação. Câmara de Educação Superior. Resolução $\mathrm{CNE} / \mathrm{CES} \mathrm{n}^{0} 1$, de 8 de junho de 2007. Estabelece normas para o funcionamento de cursos de pósgraduação lato sensu, em nível de especialização. Diário Oficial da União. 2007 jun 8;1:9.

24. Silva VO, Santana PMMA. Conteúdos curriculares e o Sistema Único de Saúde (SUS): categorias analíticas, lacunas e desafios. Interface (Botucatu) [Internet]. 2014 [acesso em 2018 mar 5];19(52):121-32. Disponível em: http://www.scielo.br/pdf/icse/v19n52/1807-5762icse-1807-576220140017.pdf

25. Secretaria de Estado da Saúde de São Paulo. Centro de Referência em Saúde do Trabalhador de São Paulo. Processo de implantação da saúde do trabalhador no SUS/SP. Rev Saúde Pública [Internet]. 2004 [acesso em 2018 mar 5];38(3):471-4. Disponível em: http://www.scielo.br/pdf/rsp/ v38n3/20668.pdf
26. Otani K. Rede de Saúde do Trabalhador para o estado de São Paulo. São Paulo em Perspectiva [Internet]. 2003 [acesso em 2018 mar 5];17(1):86-97. Disponível em: http://www.scielo.br/pdf/spp/v17n1/ v17n1a08.pdf

27. Ministério da Saúde. $2^{\circ}$ Inventário de Saúde do Trabalhador, 2010-2011: acompanhamento da Rede Nacional de Atenção Integral em Saúde do Trabalhador, 2010-2011. Brasília, DF: Ministério da Saúde; 2013.

28. Martins TB. Expansão do ensino a distância: pressupostos para sua análise e marcos regulatórios. In: Mancebo D, Silva JR, organizadores. Trabalho docente e expansão da educação superior brasileira. Rio de Janeiro: Eduerj; 2012. p. 117-146.

29. Machado MH, Oliveira ES, Moyses NMN. Tendências do mercado de trabalho em saúde no Brasil. In: Pierantoni CR, Dal Poz MR, França T, organizadores. O Trabalho em Saúde: abordagens quantitativas e qualitativas. Rio de Janeiro: Cepesc; Uerj; 2011. v. 001, p. 103-116.

30. Associação Brasileira de Educação à distância. CensoEaD.BR2010/2011 [Internet]. São Paulo: Abed; 2011 [acesso em 2018 mar 9]. Disponível em: http:// www.abed.org.br/censoead/CensoEaD2011.zip

31. Lachi RL, Rocha HV, Oeiras JYY. Avaliação de cursos a distância: uso de indicadores para assegurar qualidade. Anais do XVII Simpósio Brasileiro de Informática na Educação; 2006 nov 8-10; Brasília, DF. Porto Alegre: Ceie; 2006.

32. Ministério da Educação. Secretaria de Educação a Distância. Referenciais de qualidade para educação superior a distância [Internet]. 2007 [acesso em 2019 jun 17]. Disponível em: http://portal.mec.gov. br/seed/arquivos/pdf/legislacao/refead1.pdf

33. Souza TS, Virgens LS. Saúde do trabalhador na Atenção Básica: interfaces e desafios. Rev Bras Saúde Ocup. 2013;38(128):292-301.

34. Minayo-Gomez C, Vasconcellos LCF, Machado JMH. Saúde do trabalhador: aspectos históricos, avanços e desafios no Sistema Único de Saúde. Ciênc Saúde Coletiva. 2018;23(6):1963-70. 